\title{
Corporate Product Recall and Its Influence on Corporate Performance
}

\author{
Quanhong Liu, \\ School of Business, Jianghan University, \\ Wuhan, P.R. China
}

\author{
Xin Zhao \\ School of Business, Jianghan University, \\ Wuhan, P.R. China
}

\begin{abstract}
This paper researches the motivation of corporate product recall and its influence on corporate performance based on the perspective of corporate governance, it indicates that product recall may be driven by various kinds of corporate external factors and internal conditions, and product recall may have both of positive and negative influence on corporate performance.
\end{abstract}

Keywords: product recall; defective product; corporate crisis; corporate performance

\section{Introduction}

In recent years, domestic and foreign largescale product recall is not uncommon, causing public concern about the quality of product. With the increasing globalization of production, the increase of product complexity, the greater need for the quality and safety of the products and the close supervision of the companies and government agencies, product recall is more likely to occur in the future. The increasing product recall has caused high direct or indirect cost of the company, and also put forward the severe challenge to corporate emergency decisionmaking ability.

Product recall may cause negative market reaction to the company, but the proper product recall can enhance communication between company and consumer. It helps to obtain the understanding of consumers, and establish the positive image of company with sense of commitment, honesty and responsibility. Therefore, product recall requires a more comprehensive understanding, rather than simply as the corporate crisis event to deal with.

\section{Theoretical basis}

\subsection{Product recall}

Product recall means that when a product may pose a potential danger to consumers, the companyspontaneously or be forced recall its defective product. Product recall was once regarded as an effective tool for product quality management by the domestic and foreign government departments and academia. So the existing research on product recall mainly tends to the perspective of public relations management or law, and discusses the defects product recall administrative system and the perfection of legislation and law enforcement. From the perspective of corporate governance research product recall decision and recall management, mainly focused on the analysis of the success and failure of the recall case, summing up the experience and lessons of the company in the product recall management, and proposing the general method of the company in the scientific and effective recall management.

Smith, Thomas and Quelch (1996) indicated that although product recall is not a frequent occurrence, the company needs to establish a strategic plan and a recall process before the recall occurs. Riswadkar (1996) also considered that the company needs to establish accident handling plan for the product recall crisis. He thinks the companies can successfully deal with the recall crisis depends on whether the companies can quickly response, this response includes all the departments of the companies, and recall plan must be supported and recognized by the senior managers of the companies. Stanton (1995) pointed out that in the process of the analysis of the recall, the company executives to misunderstand the way of user thinking will lead to an increase in the risk of recall.

Based on the perspective of public relations,Gibson (1995) indicated that product recall is particularly harmful to public relations, because recall frequency is relatively high, and has potentially disastrous consequences, which requires public relations personnel to deliberate. $\mathrm{He}$ believes that although there are many complicated factors affecting the corporate product recall effect, the company in the field of communication can take a variety of techniques to improve the recall effect, improve the corporate public image.

Based on the perspective of organizational decision-making, Corbett (1996) indicated that recall decisions must be presided and participated by corporate executives, actively cooperate with the relevant departments, and supply chain of other companies should also cooperate with each other.

Based on the perspective of global supply chain risk management, Kumar and Schmitz (2011) consideredthat appropriate product traceability and appropriate recall plan as the key to supply chain risk management. Phillips (2011) 
believes that the advanced track and trace technology make the company's supply chain with more visibility, and facilitate product recalls.

Based on the perspective of corporate risk assessment, Rider and Milkovich (2000) aimed at the loss problem of consumers caused by defective products, proposed method QRA (quantitative risk analysis) for quantitative assess the potential risks of defect product.

\subsection{The influence of product recall}

For the product recall, the existing research has not formed the same conclusion. Jarrell and Peltzman (1985) believe that the product recall will affect the stock price and the market value of the company, at the same time, will significantly affect the market value of competitors. While Barber and Darrough (1996) and Koretz (1997) proved that the product recall is harmful to the market value of the company, but it has no obvious effect on the market value of competitors.

Generally it believed that the product recall may cause permanent damage to the brand, reduce profits, conduct detrimental to the reputation and goodwill with consumers. Becnel (1998) found that, due to product defects will lead to a large number of companies are facing lawsuits, which seriously affect the image of the company's reputation and damage corporate public relations. So the manufacturer should take the full test before the product listing, bear the responsibility to face the possible defects, establish the perfect legal service system, and deal with the recall litigation problem. Petersen and Kumar (2009) believe that product recall helps explain the impact of return behavior and return on the future behavior of consumers and businesses. They have proved the role of the product recall in the exchange of consumers and business processes, and said: product recall is inevitable, but the company is not the 'sin'. Triplett (1994) based on the marketing theory, research on product recall management model from the perspective of how to improve the customer loyalty. He believes an effective product recall can improve customer loyalty. Toy and Driscoll (1990) indicates that the failure of the product recall management may cause the failure of the corporate product remarket, which will endanger the survival and development of the company.

\section{The motivation for a company to recall defective products}

Product recall involves four product defects. (1)It will hurt the consumers. (2) It contains harmful substances easily to reach consumers. (3) There is a risk factor of serious injury or death caused by improper use of consumer. (4) Violation of certain product safety standards and regulations. Once these defects are exposed, it will inevitably lead to user complaints and caused the market scale of products unsalable, returns, and even lawsuits, the relevant government departments will also involve in the investigation, released a mandatory recall order. In some cases, the company executives will make the initiative or the passive recall of the defective products for the consideration of strategic trade-off and their business goals. This can be both driven by various external factors, and it may be the result of the corporate combination of the inherent conditions for the full consideration of the whole range of factors.

\subsection{External causes of product recall}

1) Supply chain management is increasingly difficult. With the deepening and refining of the international division of labor, the degree of economic globalization continues to deepen, global production networks gradually formed, product manufacturing chain constantly stretched, this has put forward higher requirements for the quality of personnel, cost control, and collaborative innovation, etc. Coupled with the integrity, complexity, dynamic ofthe supply chain itself, the difficulty of supply chain management is more prominent, the probability of the occurrence of the defective products increases, the product recall will inevitably occur.

2) Product complexity increase. Today, the product design should consider various requirements, any person or non-human factors will lead to product not up to these complex standards. It will increase the risk of failure and slow-moving of product development, increase the possibility of product recall.

3) Strengthen government supervision. As countries continue to strengthen intellectual property protection, government to speed up the environment and intellectual property rights legislation, increased regulatory constraints, strengthen supervision system, and constantly improve relevant laws and regulations. The company has to recall the product that consumes resources, pollute the environment or infringe intellectual property right.

4)Strengthen media supervision. With an increase of the media supervision, internal fine products accident after media exposure, dissemination, diffusion and amplification, it caused negative effects to the brand image and corporate reputation and the impact of its target market, companies have to recall and reprocess a lot of products.

5) Strengthen awareness of consumer rights. Today, consumers have put forward more demanding on the quality, grade and service level of the products, consumer self-protection awareness, legal sense and awareness of rights are gradually strengthen ed. For the product that endanger their personal health and property safety will take a complaint, return or sue and other way of rights protection. This led directly to the recall of defective products showing a growing trend.

6) Competitors fierce counterattack. The companies in new product development decisions, if cannot do in-depth research and analysis of competitors, then when competitors take unexpected action, the time can be taken by surprise. Or the fierce counterattack of competitors beyond the estimation, if the company is unable to meet the 
challenges of competition, its market share will be cut and recession. The surplus product recall will become inevitable.

\subsection{Internal causesof product recall}

1) The need for redesign products. Before the new design of corporate products into the market, there are a series of mature and effective market testing methods, means and models. However, the rapid changes in market environment and technology development often exceed the imagination of new product developers. In this case, the company had to be redesigned to improve the recall the new products which are not recognized and accepted by customers, to meet needs of the technical dynamic changes and the dynamic demand of the market when it into the target market again.

2) The need for pursuit of the 'recall dividend'. Successful business managers are always good at cutting costs and getting profits from all the details. The initiative to recall the fragmented defective product on the market can prevent other competitors' access to corporate technology, or to stop them from entering the market. "Recall dividend" more reflected in the recall reduced disposal costs of related wastes, extracting valuable components of products, and reduces the use of raw materials.

3) The need for reshape the image of the company. Under the rigidity restriction of the relevant product liability law,company before the government regulators to intervene actively involved in their own product crisis, through the initiative recall behavior to prove that it respects the interests of consumers, concerned about the quality of products and customer satisfaction, attention to materially affect the quality to consumers. This way can get public's trust and goodwill, enhance the operating image and market competitiveness.

\section{The reasons why acompanylack of power to recall products}

In advanced western countries, with the acceleration of government resources environmental legislation, the enhancement of consumer environmental protection and the awareness of safeguarding rights and the strengthening of media disclosure and supervision, coupled with the technical barriers and green barriers as the representative of trade protectionism, which makes the community more and more attention to the quality of products and the management and recall of defective products. General Motors, Hewlett-Packard, IBM, Siemens, as the representative of the internationally renowned companies, under the rigid constraints of the relevant product liability law and intellectual property law, based on the maintenance and expansion of the target of corporate competitive advantage, has first step into the field of recall management, and produce good economic, social and environmental benefits. But it has not aroused enough attention to company in our country. This paper considers the main reasons are as follows.

\subsection{Lack of rational understanding of product recall}

Product recall is mostly due to the existence of serious flaws in the quality of the products, coupled with the government departments ordered and notice, companies have to take to recall disposal scheme. This is rooted in the minds of consumers that the recall must be closely related to the quality of the product. Consumers are also lack of the scientific and rational understanding of the defective product recall. Coupled with media guide, they tend to product recall equated with the low credibility of companies and the poor quality of the products. In this case, in order to maintain its carefully developed and nurtured brand,the company may deliberately ignore the product damage to consumers and choose not to recall the product.

\subsection{Lack of appropriate legal institutional support}

After 30 years of reform and opening up, China's socialist market economy has made considerable progress and achievements of the world. However, the development of the socialist market economy is not perfect, the economic market-oriented is insufficient, the market system and the relevant laws and regulations are not perfect, especially the lack of substantive law involving defective product recall. Around the product damage, consumer disputes, trade disputes, product recall and compensation and other work are lack of legal system support. If this situation cannot be solved for long-term, it will make the country's defective product management and recall more difficult.

\subsection{Lack of cultural atmosphere of tolerance failure}

In a highly competitive and rapidly changing environment, management failure and product crisis is inevitable, especially for acompany which advocate adventure, progressive change, the pursuit of excellence and competitive. Allow failure, support failure, tolerance and encourage failure can make the change and innovation to achieve a breakthrough and make production more in line with consumer demand for the product. However, in our country, companies that take the initiative to recall the defective products are always in the public criticism and the questions, and the consumer purchase behavior and word of mouth are also affected. Due to the lack of the cultural atmosphere of tolerance, the companiesare hesitant to recall defective products.

\subsection{The absence of ethics and social responsibility}

Chinese companies are not good at dealing with the relationship between the organization and the natural environment, the social environment, especially the organization and the consumer. The company attaches importance to short-term interests and their own interests, and despises the legitimate interests of consumers. The whole society lacks the humanistic care, business ethics and corporate social responsibility. When the outbreak of the 
product crisis, often to take evasive or masked attitude, or forced by the government and public opinion pressure to recall the relevant issues of the relevant products. Profit maximization orientation makes the company to obliterate the products for users' injury, not willing to take action to correct the defects, make up for the losses. Only when the company does not put profit above all, will it is possible to take visionary action.

\subsection{Corporate executives pay little attention product recall}

A Company often willing to devote its human resources, capital and other factors of production on new product design and development, commercialization, product testing and import target market this 'conventional route'. In contrast, the enterprise executives generally pay less attention on the product crisis, product export markets, recall this 'reverse route'. And most companies believe that a product recall is negative, it is a management crisis, and it is not to incorporate them into the business strategy.

\subsection{Poor of supply chain integration ability}

Recall of defective products this complex business needs initiated by the core business in the supply chain, and needs the common operation of all the companies in the supply chain. Thus, communication, consultation, cooperation, integration of resources and business ability become the premise of the decision to make a recall and to carry out the work effectively. However, the companies in our country lack of the spirit of cooperation, and poor supply chain integration ability make the effective recall management become difficult.

\subsection{Poor of corporate comprehensive quality}

The product recall poses a severe challenge to the corporate emergency decision making ability. It has very high requirements of the quality of personnel, R \& D and production capacity, cost control, supply chain management system, collaborative innovation, emergency decision-making, etc. And require the reasonable control of the recall costs, the scientific assessment of the economic benefits, to ensure the probability of success on the basis of certain amount of manpower, material and financial resources. This is a major test for the overall quality of the company.

\subsection{Operational difficult of product recall}

Product development, production and delivery to the market is usually under the people's plans and control, and the time, the location, the volume and the direction of the products' outflow are substantially known and controllable. The occurrence of product recall has great concealment, uncertainty and non-procedural. Its time, place and quantity can hardly be expected, making it difficult for the company to control.

\section{The impact of product recall on corporate Performance}

The product recall decision has the important status in the corporate management, and has the remarkable influence to the corporate performance. To some extent, a product recall from high-level decisions to business executives, nearly related to corporate survival.

\subsection{The negative impact of the product recall}

1) Causing huge financial losses directly. When the product has potential defects or products pose a threat to the health of consumers and the safety of property, company had to recall the related products for all aspects of the pressure. Due to the defective products have large quantity, flow and geographical dispersion, coupled with a series of complex links, such as defective product recall, classified storage, maintenance, consolidation, etc. This needs to invest huge material resources, human resources, financial resources, organizational resources, etc., and less demand of consumer makes the product recall a huge financial loss directly.

2) Affect the brand image and corporate reputation. Product recall in the minds of the majority of customers will cause the impression that the manufacturers have quality management problems, and fraud or lack of good faith, and deliver low quality signals. Consumers will have doubts about the reliability of the product quality, reducing brand loyalty. At the same time, the negative word of mouth that the exchange and evaluation of consumer's experience in purchasing defective can also bring loss to the reputation of the company, which is very disadvantageous for the company.

3) Reduce the size of demand for the product. The sudden crisis of the product will inevitably bring about the crisis of trust. Recall of defective products makes consumers lose confidence in their products and have a negative effect on the corporate product concept or demand, the willingness to repeat purchase related products will be cut, the market volume will decline. Once the negative effects of long-term nature or difficult to reverse, the loss may be greater, and even endanger the survival and development of companies.

4)Cut corporate market share. When acorporateproduct crisis erupts, competitors will swoop through a variety of means, such as the price discounts, product diffusion, product innovation, improve service, public relations and other way to penetratethe corporate target market. Competing for the product user, and ultimately makes the organization's existing market share weakened.

5) Affect investor confidence and market capitalization. Once the products unmarketable, returns and complaints continue, demand fell sharply, market share will shrink, and reputation will be destroyed. It will affect the confidence of the investor, and the rational choice is to reduce the stock of the company. The larger range of defective product recall will cause the corporate stock a sharp decline and the 
market value of the company will shrink, which in turn will further adversely affect the product market, thus inducing the survival crisis of the company.

\subsection{The Positive impact of the product recall}

Product recall is not a simple product recycling.It needs on the basis of making the program of public relations crisis, with appropriate public relations activities,post product recall information accurately and timely, confessed the whole story, eliminate the public's doubts, save the loss of users, and guide media opinion on the favorable news for companies. With the perfect after-sale measures and compensation mechanism, the short, limited negative impact of the defective product recall will be transformed to a certain degree of positive impact.

1) Establish a good corporate image. Sustainable development has become a global consensus, and the public voice for green products and services is increasing. Company takes the initiative to recall defective products can reduce the pollution and damage to the environment, eliminate the potential threats to the health and safety of consumers, avoid major business accidents, show responsibility, credit, pay attention to security, courage, and promote harmony, visionary, commercial and industry self-awareness and other good images to the community, enhance their visibility and reputation. Moreover, the product crisis will lead to media reports and widespread concern, with the properly guide, it will enhance the visibility of the company.

2) Extend the product life cycle. When the product is a threat to consumer health and personal and property safety, and the occurrence of large-scale repairs, returns, complaints, complaints or prosecute, often it means that the product development failure and into the life cycle of recession. Products will be eliminated distribution outlets, away from the public eye. If the companies can proactively recall substandard products in advance of the product crisis, they can through product redesign and upgrade again into the target market, accept the market test, thereby greatly extending the product life cycle, save the product development costs and market development costs.

3) Improve the quality management system. Good return channels and recall system can help companies analyze the distribution of product return rates, and analyze user demand level and consumer preferences. To improve the product design, providing the first hand feedback information to the customer. This can increase customer value, promote the corporate quality management system, and improve the market competitiveness of the product.

4) Enhance communication with users. Due to serious information asymmetry, consumers can hardly know the design defect and dysfunction of the product accurately. In this case, the company with a low attitude, compassionate and friendly attitude to carry out product recall, can improve the product sales or after-sales service. Customers can smoothly return the products which are not meet their own requirements. It eliminate the worries of customers buying corporate products, improve customer satisfaction, win customers understanding and trust, increase the corporate competitive advantage, and consolidate the position of corporate market.

5) Improve employee loyalty. Corporate executives from the major and long-term interests will make the decision of initiative to recall the defective products. This visionary, courage to take, rigorous and pragmatic decision-making management style and the people-oriented, honesty and integrity of the sense of responsibility are a great encouragement to employees. Corporate self-conscious approach to telling its staff and the project team, we should be responsible for the problem what happened no matter it's a big thing or a little thing. This will greatly mobilize the enthusiasm initiative, creativity of the staff, and improve the loyalty and responsibility of the staff to the company. This is undoubtedly a huge boost to improve long-term performance of the company.

6) Transform the market accident into an internal accident. When the product has potential quality defects, the defective products information can deliver timely to the business management executives through the established recall system, which greatly increases the transparency of potential accidents. Management can improve the quality of the product in advance, optimize the allocation of resources, and eliminate the bad risk of the product. Eliminate the problem in the silent way, avoiding the outbreak of the crisis and severe product management accident. Thus transform the product crisis and the market accident into the exceptional events and internal accidents of corporate operation flow.

\section{Conclusion}

The development of market economy in the Western developed countries has bred the relatively mature product recall management system in the last hundreds of years, but the recall of defective products in China seems to be lagged behind. With the promulgation and execution of laws and regulations and departmental regulations of "Defective auto product recall management regulations"and"Drug recall management approach"etcetera, China's recall management system for the defective products also takes off and gets some achievement, but we are still far from the target of the establishment of citizen company and need the unremitting efforts of the community.

On the basis of learning from other countries, our government departments can formulate relevant product recall standards and publish product recall laws and regulations to strengthen and improve the product recall supervision management. For the company, they have to get rid of the narrow concept of the supremacy of interest and be pleasant with the product recall, carry out product recall work with a low profile, compassionate and friendly 
attitude and establish the positive image of brand with credibility, integrity and undertaking responsibility.

\section{References}

[1] A.Stanton, "Pentium Brouhaha a marketing lesson", Advertising Age, 1995, (66): 8.

[2] D. C.Gibson, "Public relations considerations of consumer product recall", Public Relations Review, 1995, 21(3): 225-240.

[3] D. E.Becnel, Jr. "An Overview of Complex Product Liability Litigation in the USA", International Journal of Fatigue, 1998, 20 (2): 93-98.

[4] G.Jarrell and S.Peltzman, "The Impact of Product Recalls on the Wealth of Sellers", Journal of Political Economy, 1985, 93(3): 512-536.
[5] G.Rider and S.Milkovich, "Quantitative Risk Analysis", Injury Control \& Safety Promotion, 2000, 7(2): 115-133.

[6] J. A. Petersen and V.Kumar, "Are Product Returns A Necessary Evil?Antecedents and Consequences", Journal of Marketing, 2009, 73(3): 35-51.

[7] M. L. Corbett, "Sleepless in Detroit", Black Enterprise, 1996, 27(2):54.

[8] N. C. Smith,R. J.Thomas, and J. A.Quelch, "A Strategic Approach to Managing Product Recalls", Harvard Business Review, 1996, 74(5):102-112.

[9] S.Kumar and S.Schmitz, "Managing Recalls in A Consumer Product Supply Chain-Root Cause Analysis and Measures to Mitigate Risks", International Journal of Production Research, 2011, 49(1): 235-253.

[10] S. Toy andL. Driscoll, "Can Perrier Purify Its Reputation?”,Business Week, 1990, (2): 45. 